Original Research Article

\title{
Prospective study of radiation related adverse events and its management in cancer patient at tertiary care teaching hospital
}

\author{
Rohit $^{1}$, Devesh Kumar Joshi ${ }^{2 *}$, Raja Paramjeet Singh Banipal ${ }^{3}$
}

${ }^{1}$ Department of Pharmacy Practice, Indo Soviet Friendship College of Pharmacy, Moga, Punjab, India ${ }^{2}$ Department of Pharmacy Practice, Shri Guru Ram Rai Institute of Technology and Science, Dehradun, Uttarakhand, India ${ }^{3}$ Department of Oncology, Guru Gobind Singh Medical College and Hospital, Faridkot, Punjab, India

Received: 18 December 2017

Revised: 18 January 2018

Accepted: 29 January 2018

\section{*Correspondence to:}

Dr. Devesh Kumar Joshi, Email: deveshkumarjoshi@ gmail.com

Copyright: (C) the author(s), publisher and licensee Medip Academy. This is an openaccess article distributed under the terms of the Creative Commons Attribution NonCommercial License, which permits unrestricted noncommercial use, distribution, and reproduction in any medium, provided the original work is properly cited.

\begin{abstract}
Background: Radiation therapy is associated with certain adverse events which may cause significant discomfort to patient and may affect patient's life. The objective of the study was to assess radiation related adverse events in the patients who are on radiation therapy and to prevent and manage these adverse events.

Methods: A prospective observational study was conducted on 193 patients receiving radiotherapy in Oncology Department at Guru Gobind Singh Medical College and Hospital, Faridkot, Punjab. One fraction (2 Gray) dose had been given to patients daily for five days in a week and monitor. The collected data was analyzed by applying IBM SPSS v21.

Results: The clinical results observed in 193 consecutive patients with follow-up of 7 weeks and graded according to RTOG Acute Radiation Morbidity Scoring Criteria. Majority of events were reported in age group of 41-60 years followed by 61-80 years, 20-40 years. Epidermal, mucosal, Genitourinary and Lower G.I. reactions are graded. The reactions managed by providing symptomatic treatment.

Conclusions: Radiation related adverse events have been found frequently in patients with radiotherapy and chemo-radiotherapy both. As the number of doses increase with time the grade of reactions also increases. Appropriate follow-up and management of these events reduces patient burden of treatment.
\end{abstract}

Keywords: Adverse events, Chemo-radiation effects, Management, RTOG, Radiotherapy

\section{INTRODUCTION}

Radiotherapy along with chemotherapy is an important approach to cancer treatment, however radiation therapy is associated with certain adverse event which may cause significant discomfort to patient and may impact on their day to day effect. The purpose of the study was to assess radiation related adverse event in patient who are on radiation therapy and its management to provide maximum benefit to the patient with minimal side effects and to monitor the impact of adverse event in cancer patients. In all the cancers, the cells start dividing into multiple immature cells in uncontrollable way and spread into nearby tissues. In the case of cancer, the process of 
formation of newer cells and apoptosis become imbalance and the body form non-stop new immature cells. ${ }^{1}$ WHO report of 2012 worldwide shows that 14.1 million new cases of cancer in 5 years, out of which 8.2 million died and 32.6 million cases living with cancer. $57 \%$ new cases of cancer, $65 \%$ cases died, and $48 \%$ cases occurred in less developed regions. Overall the incidence rate of men is $25 \%$ higher than women. ${ }^{2}$ Radiotherapy makes use of high energy waves or particles like protons, x-rays, electron beams or gamma rays for killing and destroying the cancerous cells. It is also called as radiation therapy, $\mathrm{x}$-ray therapy or irradiation. ${ }^{3}$ Main purpose of radiotherapy is to destroy or kill the cancer cells and to decrease the growth of tumor cells, without harming the nearby healthy cells and tissue. ${ }^{4,5}$ Radiotherapy is given for the cancer therapy and for adjuvant therapy i.e. treatment after the main therapy to target or kill the remaining cancer cells. ${ }^{6,7}$ For some patients radiation therapy is sufficient to cure disease and for some patients it require in combination with immunotherapy, chemotherapy, hormone therapy or surgery. ${ }^{7}$

Adverse event is defined according to Common Terminology Criteria for Adverse Events, as it is any unfavorable and unintended sign (including an abnormal laboratory finding), symptom, or disease temporally associated with the use of a medical treatment or procedure that may or may not be considered related to the medical treatment or procedure. ${ }^{8}$ According to National cancer institute an adverse event is unexpected medical problem that happens during treatment with a drug or other therapy. ${ }^{9}$

For skin toxicity grade 0 means no change over baseline, grade I means Follicular, faint or dull erythema/ epilation/ decreased sweating/ dry desquamation, grade II means Tender or bright erythema, moderate edema / patchy moist desquamation, grade III means Confluent, pitting edema, moist desquamation other than skin folds and grade IV means Ulceration, necrosis, hemorrhage. For mucosal toxicity grade 0 means no change over baseline, grade I means injection/ may experience mild pain not requiring analgesic, grade II means patchy mucositis which may produce an inflammatory serosanguinitis discharge/ may experience moderate pain requiring analgesia, grade III means confluent fibrinous mucositis/ may include severe pain requiring narcotic and grade IV means Ulceration, hemorrhage or necrosis. For genitourinary toxicity grade 0 means No change, grade I means frequency of urination or nocturia twice pretreatment habit/ dysuria, urgency not requiring medication, grade II means frequency of urination or nocturia which is less frequent than every hour, dysuria, urgency, bladder spasm requiring local anesthetic (e.g., Pyridium), grade III means frequency with urgency and nocturia hourly or more frequently/ dysuria, pelvis pain or bladder spasm requiring regular, frequent narcotic/gross hematuria with/ without clot passage and grade IV means hematuria requiring transfusion/ acute bladder obstruction not secondary to clot passage, ulceration or necrosis. For lower gastrointestinal including pelvis toxicity grade 0 means no change, grade I means Increased frequency or change in quality of bowel habits not requiring medication/ rectal discomfort not requiring analgesics, grade II means diarrhea requiring Para sympatholytic drugs (e.g., Lomotil)/ mucous discharge not necessitating sanitary pads/ rectal or abdominal pain requiring analgesics, grade III means Diarrhea requiring parenteral support/ severe mucous or blood discharge necessitating sanitary pags/abdominal distention (flat plate radiograph demonstrates distended bowel loops) and grade IV means Acute or sub-acute obstruction, fistula or perforation; gastrointestinal bleeding requiring transfusion; abdominal pain or tenesmus requiring tube decompression or bowel diversion. Any toxicity which caused death is graded V. All toxicities Grade III, IV or V must be verified by the Principal Investigator. ${ }^{10}$

\section{METHODS}

The study was conducted at Department of Oncology, Guru Gobind Singh Medical College and Hospital (GGSMCH), Faridkot. This was a prospective observational study. The study was carried out for a period of six months i.e. November 2015 to April 2016. Patients receiving radiation therapy and chemotherapy with radiotherapy for treatment of cancer both were included. Patients taking radiation treatment from Cobalt 60 and Linear accelerator (LINAC) machine were included. Daily one fraction (2 Gray) of dose has given to patients, five days in a week.

Patient receiving only chemotherapy, pregnant, lactating and nursing mother, children less than 18 years old, patient more than 85 years old, psychiatric patient and palliative patients were excluded. All the relevant data was collected from patient treatment chart, patient radiation chart, patient case sheet, interviewing the patients and communicating with senior radiation oncologist. Institutional Human Ethical Committee of ISF College of Pharmacy, Moga, Punjab approved the study ref. no: ISFCP/IEC/2015-16/P-07 on dated: 15-Sep-2015. A specially designed data collection form was developed. It includes demographic details like name, age, gender, medical history, height, weight, clinical data such as diagnosis, therapeutic details such as radiotherapy or chemo-radiotherapy, radiotherapy details such as dose, fraction, duration, machine used, adverse events observed, grade, type of treatment given, outcome, and management. The same details were documented electronically in specially design data base using SPSS v21.All the patients who were on radiation therapy or chemo-radiotherapy were monitored as per Radiation Therapy Oncology Group (RTOG) Acute Radiation Morbidity Scoring Criteria for occurrence of radiation related epidermal, mucosal, genitourinary and lower G.I. reactions if any, and were assessed for different grades. Management of the reactions taken on the basis of grade of reaction and follow-up. The collected data was analyzed by applying IBM SPSS v21 statistics software for windows. 


\section{RESULTS}

A total 193 patients satisfied inclusion criteria, were included in the study and shown adverse event induced by the radiation therapy.

Table 1: Patient's demographic and related information.

\begin{tabular}{|c|c|c|c|}
\hline \multicolumn{2}{|c|}{ Demographic data } & $\begin{array}{l}\text { Number } \\
\text { of } \\
\text { patients }\end{array}$ & $\begin{array}{l}\text { Percentage } \\
\text { of patients }\end{array}$ \\
\hline \multirow{5}{*}{$\begin{array}{l}\text { Age } \\
\text { (years) }\end{array}$} & $<20$ & 00 & $0.0 \%$ \\
\hline & $20-40$ & 26 & $13.5 \%$ \\
\hline & $41-60$ & 114 & $59.1 \%$ \\
\hline & $61-80$ & 49 & $25.4 \%$ \\
\hline & $>80$ & 04 & $2.1 \%$ \\
\hline \multirow{2}{*}{ Gender } & Female & 147 & $76.2 \%$ \\
\hline & Male & 46 & $23.8 \%$ \\
\hline \multirow{2}{*}{$\begin{array}{l}\text { Payment } \\
\text { scheme }\end{array}$} & $\begin{array}{l}\text { Government } \\
\text { insured }\end{array}$ & 174 & $90.2 \%$ \\
\hline & Self-payment & 19 & $9.8 \%$ \\
\hline \multirow{4}{*}{$\begin{array}{l}\text { Social } \\
\text { history }\end{array}$} & No Addiction & 144 & $74.6 \%$ \\
\hline & Tobacco & 11 & $5.7 \%$ \\
\hline & Alcoholic & 33 & $17.1 \%$ \\
\hline & Smoker & 05 & $2.6 \%$ \\
\hline
\end{tabular}

Breast cancer was most commonly reported $(n=82,42.5 \%)$, followed by head and neck cancer $(n=53,27.5 \%)$ and cervix cancer $(n=47,24.4 \%) .70 \%$ of the patients $(n=136)$ were on radiotherapy alone and $30 \%$ patients $(n=57)$ were on radiotherapy with chemotherapy. Linear accelerator $(n=129,66.8 \%)$ is the most common used instrument for radiotherapy followed by cobalt $60(n=64,33.2 \%)$.

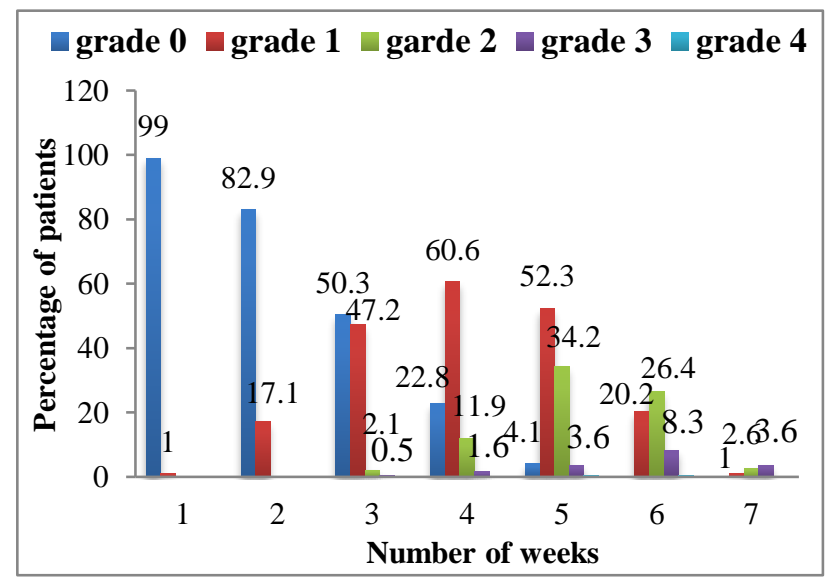

Figure 1: Epidermal reactions in cancer patients.

As shown in Figure 1, according to RTOG criteria out of 193 patients on week $1,99 \%$ patients were showing grade 0 and $1 \%$ patients were showing grade 1 epidermal reactions. On week $2,82.9 \%$ patients were showing grade 0 and $17.1 \%$ patients were showing grade 1 epidermal reactions. On week $3,50.3 \%$ patients were showing grade
$0,47.2 \%$ patients were showing grade $1,2.1 \%$ patients were showing grade 2 and $0.5 \%$ patients were showing grade 3 epidermal reactions. On week 4, 22.8\% patients were showing grade $0,60.6 \%$ patients were showing grade $1,11.9 \%$ patients were showing grade 2 and $1.6 \%$ patients were showing grade 3 epidermal reactions. On week 5, $4.1 \%$ patients were showing grade $0,52.3 \%$ patients were showing grade $1,34.2 \%$ patients were showing grade 2 , $3.6 \%$ patients were showing grade 3 and $0.5 \%$ patients were showing grade 4 epidermal reactions. On week 6 , $20.2 \%$ patients were showing grade $1,26.4 \%$ patients were showing grade $2,8.3 \%$ patients were showing grade 3 and $0.5 \%$ patients were showing grade 4 epidermal reactions. On week $7,1 \%$ patients were showing grade $1,2.6 \%$ patients were showing grade 2 and $3.6 \%$ patients were showing grade 3 epidermal reactions.

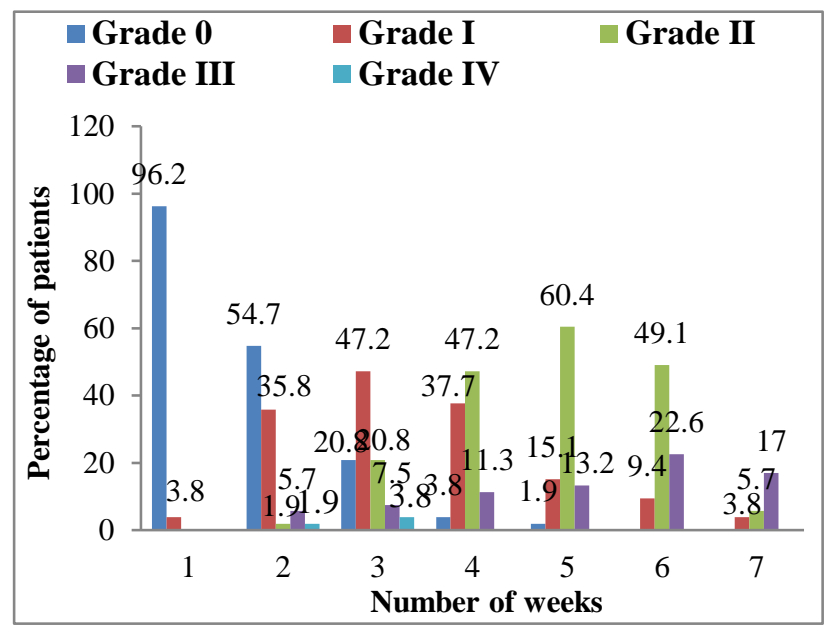

Figure 2: Mucosal reactions in head and neck cancer patients.

As shown in Figure 2, according to RTOG criteria out of 53 patients with Head and Neck cancer at week 1, 96.2\% patients shown grade 0 and $3.8 \%$ patients shown grade 1 mucosal reaction. On week $2,54.7 \%$ patients have shown grade $0,35.8 \%$ patients shown grade $1,1.9 \%$ patients shown grade $2,5.7 \%$ patients shown grade 3 and $1.9 \%$ patients shown grade 4 mucosal reactions. On week 3 , $20.8 \%$ patients have shown grade $0,47.2 \%$ patients shown grade $1,20.8 \%$ patients shown grade 2 and $7.5 \%$ patients shown grade 3 and $3.8 \%$ patients shown grade 4 mucosal reactions. On week $4,3.8 \%$ patients have shown grade 0 , $37.7 \%$ patients shown grade $1,47.2 \%$ patients shown grade 2 and $11.3 \%$ patients shown grade 3 mucosal reactions. On week $5,1.9 \%$ patients have shown grade 0 , $15.1 \%$ patients shown grade $1,60.4 \%$ patients shown grade 2 and $13.2 \%$ patients shown grade 3 mucosal reactions. On week $6,9.4 \%$ patients have shown grade 1 , $50.9 \%$ patients shown grade 2 and $22.6 \%$ patients shown grade 3 mucosal reactions. On week $7,3.8 \%$ patients have shown grade $1,5.7 \%$ patients shown grade 2 and $17.0 \%$ patients shown grade 3 mucosal reactions.

As shown in Figure 3, according to RTOG criteria out of 58 patients with pelvic cancer at week 1, 100\% shown 
grade 0 genitourinary reactions. On week 2, $96.6 \%$ patients shown grade 0 and $3.4 \%$ patients shown grade 1 genitourinary reactions. On week $3,89.7 \%$ patients have shown grade $0,8.6 \%$ patients shown grade 1 and $1.7 \%$ patients shown grade 2 genitourinary reactions. On week 4, $72.4 \%$ patients have shown grade $0,24.1 \%$ patients shown grade 1 and $3.4 \%$ patients shown grade 2 genitourinary reactions. On week $5,58.6 \%$ patients have shown grade $0,36.2 \%$ patients shown grade 1 and $5.2 \%$ patients shown grade 2 genitourinary reactions. On week $6,32.8 \%$ patients have shown grade $0,58.6 \%$ patients shown grade 1 and $8.6 \%$ patients shown grade 2 genitourinary reactions.

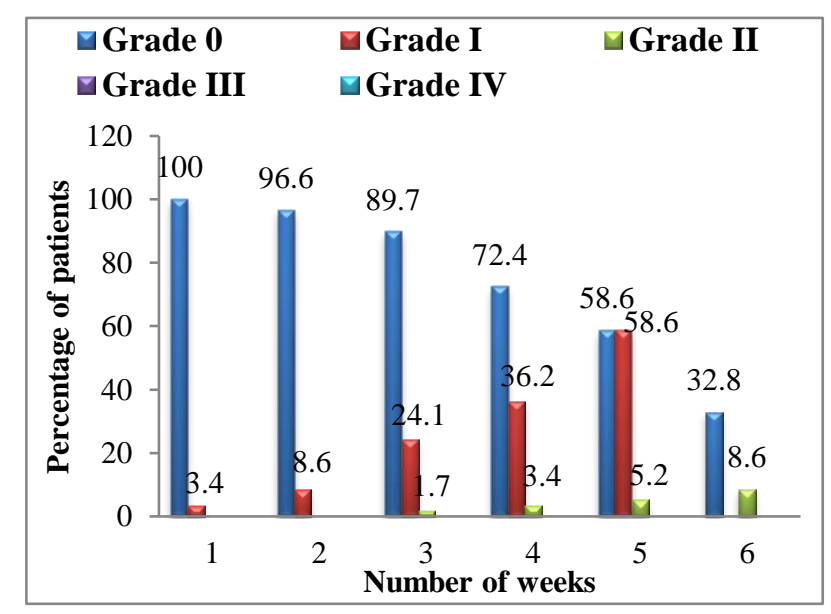

Figure 3: Genitourinary reactions in pelvic cancer patients.

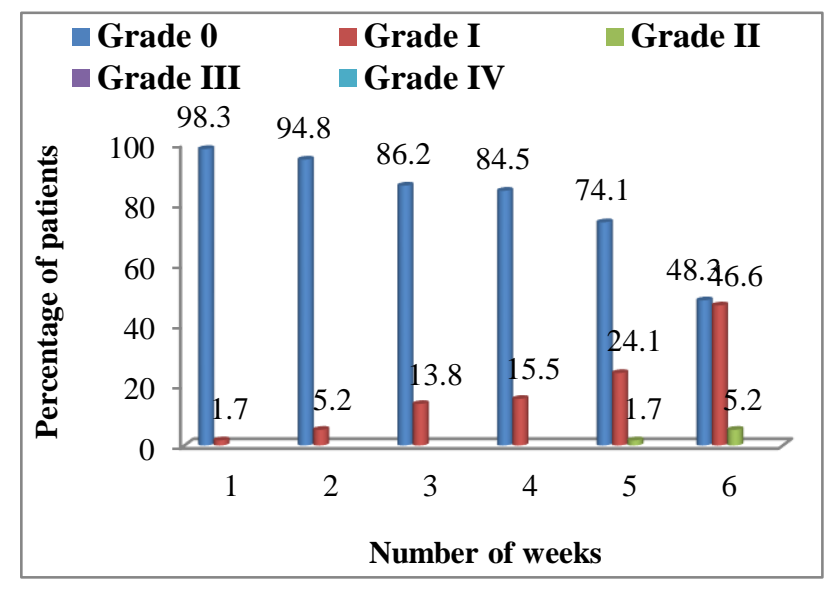

Figure 4: Lower G.I. reactions in pelvic cancer patients.

As shown in Figure 4, according to RTOG criteria out of 58 patients with pelvic cancer at week 1, 98.3\% shown grade 0 and $1.7 \%$ patients showed grade 1 lower G.I. reactions. On week $2,94.8 \%$ patients shown grade 0 and $5.2 \%$ patients shown grade 1 lower G.I. reactions. On week $3,86.2 \%$ patients have shown grade 0 and $13.8 \%$ patients shown grade 1 lower G.I. reactions. On week 4, 84.5\% patients have shown grade 0 and $15.5 \%$ patients shown grade 1 lower G.I. reactions. On week $5,74.1 \%$ patients have shown grade $0,24.1 \%$ patients shown grade 1 and $1.7 \%$ patients shown grade 2 lower G.I. reactions. On week $6,48.3 \%$ patients have shown grade $0,46.6 \%$ patients shown grade 1 and $5.2 \%$ patients shown grade 2 lower G.I. reactions.

\section{Management of adverse event}

Table 2: Treatment of radiation induced epidermal reactions.

\begin{tabular}{|lll|}
\hline Grade & $\begin{array}{l}\text { Number of } \\
\text { patients }\end{array}$ & $\begin{array}{l}\text { Management } \\
\text { No medicine }\end{array}$ \\
\hline 2 & 117 & $\begin{array}{l}\text { Gentian violet application on } \\
\text { affected part }\end{array}$ \\
\hline 3 & 66 & $\begin{array}{l}\text { Stop the radiation 3-4days } \\
\text { and gentian violet paint } \\
\text { application on affected part }\end{array}$ \\
\hline 4 & 01 & $\begin{array}{l}\text { Stop the radiation 3-4days } \\
\text { and gentian violet paint }+ \\
\text { metronidazole application on } \\
\text { affected part }\end{array}$ \\
\hline
\end{tabular}

Table 3: Treatment of radiation induced mucosal reactions.

\begin{tabular}{|lll|}
\hline Grade & $\begin{array}{l}\text { Number of } \\
\text { patients }\end{array}$ & $\begin{array}{l}\text { Management } \\
\text { Suggested steam inhalation } \\
\text { and gargles of lukewarm water } \\
+2 \text { pinch table salt with } \\
\text { beginning of radiotherapy }\end{array}$ \\
\hline 1 & 53 & Vitamin B complex \\
\hline 2 & 32 & $\begin{array}{l}\text { Vitamin B complex }+ \\
\text { Benzylalkonium chloride }\end{array}$ \\
\hline 3 & 12 & $\begin{array}{l}\text { Stop the radiation for 3-4 days } \\
\text { and cyclohexidine gargles or } \\
\text { betadine gargles }\end{array}$ \\
\hline 4 & 02 & $\begin{array}{l}\text { Stop the radiation for 3-4 days } \\
\text { and Cotromazole }+ \\
\text { Dexamithasone + Ranitidine } \\
\text { (candid mouth paint + Dexona } \\
\text { + Rantac) } \\
\text { Lignocain }+ \text { Vitamin B } \\
\text { complex + pantoprazole }\end{array}$ \\
\hline
\end{tabular}

The epidermal reactions of the breast cancer, head and neck cancer and pelvic cancer patients had managed by providing symptomatic treatment. Patients had advised that do not apply any cream, lotion or oil to the radiation treated area, because it causes increase in the intensity of the radiation on epidermal surface. This may damage epidermal surface to high grade. The patients who developed grade 3 or 4 reactions, the radiation dose stopped for 3-4 days, this help in the stabilization of reactions which was further not increased on continuing the radiation treatment. Table 2 showing the number of 
patients treated for different grades of reaction management.

The patients of head and neck cancer had advised to take steam inhalation and gargles of lukewarm water with 2 pinch table salt with beginning of radiotherapy for the prevention of mucosal reactions. The patients who developed grade 3 or 4 reactions, the radiation dose stopped for 3-4 days, this help in the stabilization of reactions which was further not increased on continuing the radiation treatment. The management treatment given for the different grades of mucosal reactions has shown in Table 3.

Table 4: Treatment of radiation induced genitourinary reactions.

\begin{tabular}{|lll|}
\hline Grade & $\begin{array}{l}\text { Number of } \\
\text { patients }\end{array}$ & Management \\
\hline 0 & 58 & $\begin{array}{l}\text { Suggested to drink plenty of } \\
\text { water }\end{array}$ \\
\hline 1 & 34 & Amikacin \\
\hline 2 & 05 & $\begin{array}{l}\text { Stop the radiation and } \\
\text { amikacin }\end{array}$ \\
\hline
\end{tabular}

Table 5: Treatment of radiation induced lower G.I. reactions.

\begin{tabular}{|lll|}
\hline Grade & $\begin{array}{l}\text { Number of } \\
\text { patients }\end{array}$ & Management \\
\hline 0 & 58 & $\begin{array}{l}\text { suggested to drink plenty of } \\
\text { water }\end{array}$ \\
\hline 1 & 27 & Loperamide (Eldoper) \\
\hline 2 & 03 & $\begin{array}{l}\text { Stop the radiation and } \\
\text { Ranitidine + Loperamide } \\
\text { (Rantac + Eldoper) }\end{array}$ \\
\hline
\end{tabular}

The patients of pelvic cancer had developed genitourinary and lower G.I. reactions. Patients advised to drink plenty of water for the prevention of radiation reactions. The patients who developed grade 3 or 4 reactions, the radiation dose stopped for 3-4 days, this help in the stabilization of reactions which was further not increased on continuing the radiation treatment. The management treatment given for the different grades of reactions for genitourinary and lower G.I. has shown in Table 4 and 5 respectively.

Table 6: Outcome of the events.

\begin{tabular}{|lll|}
\hline Outcomes & $\begin{array}{l}\text { Number of } \\
\text { patients }\end{array}$ & $\begin{array}{l}\text { Percentage of } \\
\text { patients }\end{array}$ \\
\hline Recovered & 57 & $29.53 \%$ \\
\hline Recovering & 87 & $45.07 \%$ \\
\hline Continuing & 28 & $14.50 \%$ \\
\hline Unknown & 17 & $8.80 \%$ \\
\hline N/A & 04 & $2.07 \%$ \\
\hline
\end{tabular}

Outcome of the adverse events after its management and symptomatic treatment majority of the patients were recovering $(n=87,45.07 \%)$ followed by recovered $(n=57$, $29.53 \%)$ then continuing $(\mathrm{n}=28,14.50 \%)$, unknown $(\mathrm{n}=17$, $8.80 \%)$ and N/A $(n=4,2.07 \%)$.

\section{DISCUSSION}

The result of our study suggests that patient undergoing radiation therapy is at increased risk of several acute adverse effects. Majority of events were reported in age group of $41-60$ years $(59.1 \%)$ followed by $61-80$ years (25.4\%), 20-40 years (13.5\%). This could be explained by number hospital admission or the chance of getting disease in individuals or these age groups. The result is in concordance with recent cancer statistics obtained from government of U.K. in which about $53 \%$ of the cancer occurred in people age group of 51-70 years and 10\% in patients belonging to age group 30-69 years. ${ }^{11}$

Study was conducted by Singla $\mathrm{S}$, et al to evaluate the severity of oral mucositis and xerostomia at different doses of radiation therapy among patients of head and neck cancer. Evaluation for oral mucositis was done at 10 gray, 20 gray, 40 gray and 60 gray. The mean value of oral mucositis was $0.00,0.00,1.84,3.84$ at 10, 2040 and 60 gray respectively. They found that there was no oral mucositis at 10 and 20 gray. Out of 25 patients at 40 gray, 21 patients were having gade- 2 mucositis and 4 patients were having grade- 1 mucositis. Similarly, out of 25 patient at 60 gray 21 were having grade- 4 mucositis and 4 were having grade- 3 mucositis. ${ }^{12}$ In our study, evaluation for oral mucositis was done on weekly basis at dose 2 gray per day. Out of 53 patients, at week 1, 2 patients have shown grade 1 mucositis. On second week, 19 patients shown grade 1, 1 patient has shown grade 2, 3 patients shown grade 3 and 1 patient shown grade 4 mucositis. On $3^{\text {rd }}$ week, 25 patients have shown grade 1,11 patients shown grade 2 and 4 patients shown grade 3 and 2 patients shown grade 4 mucositis. On $4^{\text {th }}$ week, 20 patients have shown grade 1, 25 patients shown grade 2 and 6 patients shown grade 3 mucositis. On $5^{\text {th }}$ week, 8 patients have shown grade 1, 32 patients shown grade 2 and 60 patients shown grade 3 mucositis. On $6^{\text {th }}$ week, 5 patients have shown grade 1,26 patients shown grade 2 and 12 patients shown grade 3 mucositis. On $7^{\text {th }}$ week, 2 patients have shown grade 1, 3 patients shown grade 2 and 9 patients shown grade 3 mucositis. A study conducted on 53 head and neck cancer patients and Grade 3-4 mucositis was observed in 21 patients $(39.6 \%) .51$ of the patients $(96.2 \%)$ received the full dose of RT (70 Gy) over a median period of 50 days (range 46-62 days). ${ }^{13}$

In a study shows total 157 patients (56\%) experienced Radiation Therapy Oncology Group Grade 0 or I acute skin toxicity; 102 patients (43\%) developed Grade II acute skin toxicity and only $3(1 \%)$ experienced Grade III toxicity. The cosmetic results at 12 months (95 patients analyzable) were rated as excellent/good in 94 patients (99\%). No skin telengiectasias, significant fibrosis, or 
persistent breast pain was noted. ${ }^{14}$ In our study on grade I reactions no medicine prescribed, on grade II reactions gentian violet paint was prescribed, on grade III reactions radiation was stopped for 3-4days and gentian violet paint was prescribed and on grade IV reactions radiation was stopped for 3-4 days and gentian violet paint + metronidazole was prescribed. The outcome result at $7^{\text {th }}$ week of treatment (76 patients who develop skin toxicity were analyzable) was good 43 patients recovered and 33 patients recovering.

Duration of study was confined only for 6 months.

Limitation of the study was due to short duration of study we could not identify delayed adverse event and adverse events occurred after discharging patients were not reported.

\section{CONCLUSION}

The patients observed with follow-up of 7 weeks. Radiation related adverse events were found frequently in patients with radiotherapy and chemo-radiotherapy both. The patients which are on radiation therapy were definitely develop the adverse reactions therefore patients on the radiation and chemo-radiation therapy required proper monitoring and careful follow-up to identify radiation induced toxicity. Appropriate follow-up and management of these events reduces patient burden of treatment.

\section{Funding: No funding sources}

Conflict of interest: None declared

Ethical approval: The study was approved by the Institutional Human Ethical Committee of ISF College of Pharmacy, Moga, Punjab (ISFCP/IEC/2015-16/P-07)

\section{REFERENCES}

1. NIH. What Is Cancer?: National Cancer Institute; 2016 [updated 9 February 2015; cited 201625 February]. Available at: http://www.cancer.gov/about-cancer/what-is-cancer.

2. WHO. All Cancers (excluding non-melanoma skin cancer) Estimated Incidence, Mortality and Prevalence Worldwide in 2012: GLOBOCAN 2012: International Agency for Research on Cancer; 2016 [cited 2016,25 February]. Available at: http://globocan.iarc.fr/Pages/fact_sheets_cancer.aspx.

3. American cancer society. A Guide to Radiation therapy American Cancer Society; 2015 [cited 2015, 22-September]. Available at: http://www.cancer.org/acs /groups/cid/documents/webcontent/003028-pdf.

4. Powlis WD, Altschuler MD, Censor Y, Buhle EL. Semi-automated radiotherapy treatment planning with a mathematical model to satisfy treatment goals. International Journal of Radiation Oncology Biology Physics. 1989;16(1):271-6.
5. Zelefsky MJ, Chan H, Hunt M, Yamada Y, Shippy AM, Amols H. Long-term outcome of high dose intensity modulated radiation therapy for patients with clinically localized prostate cancer. The Journal of urology. 2006;176(4):1415-9.

6. Allen AM, Czerminska M, Jänne PA, Sugarbaker DJ, Bueno R, Harris JR, et al. Fatal pneumonitis associated with intensity-modulated radiation therapy for mesothelioma. International Journal of Radiation Oncology Biology Physics. 2006;65(3):640-5.

7. Whitney CW, Sause W, Bundy BN, Malfetano JH, Hannigan EV, Fowler Jr WC, et al. Randomized comparison of fluorouracil plus cisplatin versus hydroxyurea as an adjunct to radiation therapy in stage IIB-IVA carcinoma of the cervix with negative paraaortic lymph nodes: a Gynecologic Oncology Group and Southwest Oncology Group study. Journal of Clinical Oncology. 1999;17(5):1339.

8. US Department of Health and Human Services. Common terminology criteria for adverse events (CTCAE) version 4.0. National Institutes of Health, National Cancer Institute. 2009;4(03).

9. NIH. NCI Dictionary of Cancer Terms: National cancer institute; 2016 [updated 9 February 2015; cited 2016, 5-April]. Available at: http://www.cancer.gov/publications/dictionaries/canc er-terms?cdrid $=444960$.

10. Cox JD, Stetz J, Pajak TF. Toxicity criteria of the radiation therapy oncology group (RTOG) and the European organization for research and treatment of cancer (EORTC). International Journal of Radiation Oncology Biology Physics. 1995;31(5):1341-6.

11. U.K. (2013, 10 July 2015). Cancer Registration Statistics, England: 2013. Retrieved 26-April, 2016. Available at: http://www.ons.gov.uk/peoplepopulation andcommunity/healthandsocialcare/conditionsanddis eases/bulletins/cancerregistrationstatisticsengland/20 15-07-10.

12. Singla S, Naik V, Kini R, Shetty A. Cumulative dose related adverse effects of radiation therapy on oral cavity. International Journal of Medical and Applied Sciences. 2014;3(2):106-10.

13. Homma A, Inamura $\mathrm{N}$, Oridate $\mathrm{N}$, Suzuki $\mathrm{S}$, Hatakeyama H, Yasuda MT. Concomitant weekly cisplatin and radiotherapy for head and neck cancer. Japanese Journal of Clinical Oncology. 2011;41(8):980-6.

14. Vicini FA, Sharpe M, Kestin L, Martinez A, Mitchell CK, Wallace $\mathrm{M}$, et al. Optimizing breast cancer treatment efficacy with intensity-modulated radiotherapy. International Journal of Radiation Oncology Biology Physics. 2002;54(5):1336-44.

Cite this article as: Rohit, Joshi DK, Banipal RPS. Prospective study of radiation related adverse events and its management in cancer patient at tertiary care teaching hospital. Int J Basic Clin Pharmacol 2018;7:451-6. 